\title{
Prospect Value Analysis of Food Safety Punitive Damage System in China
}

\author{
Xiao Hanjie \\ Quality Development Institute \\ KMUST \\ Kunming, China \\ e-mail: hanjiesmile@163.com
}

Chen Yao

Research Center for Pharmaceutical Care and Quality Management

The First People's Hospital of Yunnan Province

Kunming, China

e-mail: chyhdd@sina.com

\author{
Xu Jianxin* \\ Quality Development Institute \\ KMUST \\ Kunming, China \\ e-mail: kmustxiao2014@126.com
}

\begin{abstract}
The effectiveness and deterrence of food safety punitive damage system in China have been widely questioned in academic circle. Based on the Prospect Theory, this paper gives an analysis of the causes of frequent food safety incidents with the current punitive damage system in China. Simulation analysis is adopted to acquire the best range of punitive damage coefficient. And it proposes a flexible punitive damage calculation method with more discretionary space. Furthermore, it presents suggestions for improving the existing food safety punitive damage system.
\end{abstract}

Keywords-food safety; prospect theory; punitive damage; simulation; prospect value analysis

\section{INTRODUCTION}

The low illegal cost is the main reason for the occurrence of violations of food safety in China[1]. To increase the illegal cost of food enterprises can effectively curb illegal behaviors of food safety, which is the common view of scholars home and abroad. Experience of safeguarding consumers' rights in developed countries has indicated that the effective approach to increasing the illegal cost is to introduce the punitive damage system. The punitive damage system has been implemented in the field of food safety in China. But recently, the frequent occurrence of food safety issues arises the social concern for the punitive damage system in Food Safety Law of the People's Republic of China.

The punitive damage system in Food Safety Law of the People's Republic of China, i.e., paragraph 2 of Article 96 , states that "when any manufacturer produces any food not conforming to the food safety standards or sells any food knowing its nonconformity with the food safety standards, the customer can demand the manufacturer or the seller to pay a penalty 10 times of the paid amount, in addition to the compensation for the loss thereof."[2], whose legislative intent is to increase the illegal cost of food enterprises, strengthen the law's deterrence to the business entities of food production and safeguard the rights of consumers[3]. The establishment of punitive damage system of national food safety is of great significance to safeguarding the interests of consumers. However, the statement of "a penalty 10 times of the paid amount" is far behind from the punitive damage used in Britain and America. Chinese scholars have raised questions and reviewed the punitive damage system. Wang Jun and Zhong Juan[4] (2012) argues that the punitive damage system is not reflecting the protection of consumers' rights and has not resolved the problems of food safety, and therefore, a new food safety punitive damage system should be reestablished; Li Xiang[5] (2013) thinks the legislation of punitive damage is not that scientific, and there are many flaws in the amount defined and implementing methods; Yan Miao[6] (2014) holds the view that the rule of "a penalty 10 times of the paid amount" in practice lacks the flexibility of application, which means this system is not able to meet the adequate compensation needs of consumer victims and is unqualified to make food enterprises alerted. Reasonable calculation criterion and approaches of punitive damage are directly related to the validity of this system. Currently, there are two approaches internationally [7]: (1) taking the actual loss of victim as the basic standard of punitive damage amount; (2) an elastic calculation method of punitive damage with discretionary space. The above two methods have their own advantages and there is no consensus reached about the calculation of punitive damage.

The above literature of punitive damage is mainly from the perspectives of law and economics. There are few to analyze the effectiveness of punitive damage and the psychological perception of the responsible party of food safety from the perspective of psychology and behavioral science. As a theory of behavioral economics, 
the Prospect Theory is capable to well depict the value perception of gain and loss of behavioral party. On this basis, this paper adopts the value function in prospect theory to depict food enterprise entities' value perception of "10 time penalty". Effect model is constructed. Besides, the prospect value of " 10 times penalty" is analyzed from the perspective of psychology and behavioral science. Finally, simulation analysis is used to improve the punitive damage system of food safety in China.

\section{CAUSES ANALYSIS OF FOOD SAFETY VIOLATIONS BASED ON THE PROSPECT THEORY}

\section{A.The Prospect Theory}

Expected utility theory cannot explain why people are deviated from rationality when people make decisions that involve risk. The prospect theory, created by Kahneman and Tversky[9], is a psychology- cally more accurate description of decision making compared to the expected utility theory. The prospect theory mainly focuses on the value function and weighting function of subjective probability. Prospect value $V=\sum_{i} \pi\left(p_{i}\right) v\left(x_{i}\right)$, where $v(x)$ is the value function, $\pi(p)$ is the subjective probability function, an increasing function of probability p.

$$
v(x)=\left\{\begin{array}{cc}
x^{\alpha} & x \geq 0 \\
-\lambda(-x)^{\beta} & x \leq 0
\end{array}\right.
$$

In equation (1), $\alpha$ and $\beta$ stand for the coefficients of risk appetite and risk aversion respectively. Value function is empirical. Most people make risk decisions will (1) be averse to the risk in face with gains; (2) be inclined to risk when facing losses; (3) be more painful when suffering the same losses as gains, i.e., people are more sensitive with the losses.

$$
\pi(p)=\frac{p^{\gamma}}{\left(p^{\gamma}+(1-p)^{\gamma}\right)^{\frac{1}{\gamma}}}
$$

In equation (2), $\gamma$ is risk attitude coefficient of gains and $\delta$ is risk attitude coefficient of losses. The value function $\mathrm{S}$ curve is shown in figure 1.

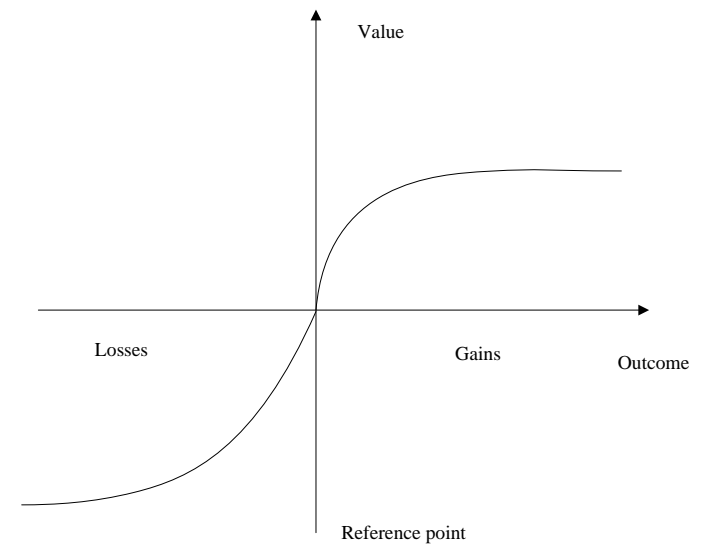

Figure 1. The value function $S$ curve

\section{B. Causes analysis of food safety violations}

By analyzing food safety violation incidents in recent years, we found that the fundamental reason for these incidents lies in benefit distribution. Food manufacturer is the "homooeconomicu" with bounded rationality who pursues the maximum of his profits. Legal restriction on the production and operation of food enterprises depends on their deliberation of value perception between illegal gains and illegal cost[10]. In light of the relation of illegal cost and illegal gains, there are several situations when food enterprises make decisions.

1.Value perception of illegal cost $<$ Value perception of illegal gains

When food enterprises believe that illegal production and management will bring more benefits than the illegal cost, they are more likely to have illegal behaviors. The ultimate purpose of food production is to achieve the maximum of profits. Therefore, enterprises are willing to take risks to gain illegal benefits, which further leads to a less safer food market.

2. Value perception of illegal cost $=$ Value perception of illegal gains

When food enterprises believe that gains from illegal production and operation will bring the same benefits as the illegal cost, though they have realized the risk cost of illegal behaviors, they always incline to have risk appetite based on the prospect theory. Therefore, driven by the huge profits, food enterprises will continuously make violations. Under this circumstance, safety of food market decreases.

3. Value perception of illegal cost $>$ Value perception of illegal gains

When food enterprises believe that gains from illegal production and operation will bring less benefits than the illegal cost, they will incline to adhere to legal production based on the recognition that illegal behaviors will lead to great loss. Therefore, food market will get improved.

From the perspective of illegal cost value perception, to increase the anticipated illegal cost of food manufacturers will effectively curb the occurrence of food safety violations. Experiences of safeguarding consumers' legitimate rights in developed countries in Europe and America indicates that the introduction of punitive damage system is an effective approach to increase illegal cost. Therefore, the food safety punitive damage system needs improving to increase the illegal cost of food enterprises and meanwhile protect the legitimate rights and interests of consumers.

\section{SIMULATION ANALYSIS OF THE PROSPECT VALUE OF THE AMOUNT OF PUNITIVE DAMAGE}

Usually, a punitive damage system has three fundamental functions: complementary function, punitive function and incentive function.[11] (1)Complementary function. Civil compensation in China is complementary; and the damage system is established based on complementary system. Therefore the damage amount for victims whose rights are violated is always higher than his 
loss. (2)Punitive function. Punitive damage is to punish the violator and increase his illegal cost, which is to achieve the fundamental purpose of punitive damage system, i.e. moderate deterrence. (3) Incentive function. Punitive damage system can help those people whose rights are violated to get more compensation, which incites them to take more active moves to safeguard the legitimate rights. Based on the above three attributes, the implementation of punitive damage system can decrease food safety incidents and protect the rights of consumers theoretically. However, the frequent occurrence of food safety violations in recent years shows it is not optimistic in terms of the protection of consumers' rights. In China, food safety punitive damage system has an unsatisfactory influence on the food market, with violations prevailing.

The aim of moderate deterrence is to prevent accidents. Its key is the establishment of the amount of punitive damage. If the setting amount of punitive damage is lower than the damage of right violation, the deterrence is small, which will lead to larger probability of right violation incidents; if the setting amount of punitive damage is higher than the damage, over-deterrence occurs, which will lead to the decrease of the enthusiasm of enterprises and the sound development of the industry[7]. Therefore, a scientific and reasonable establishment of punitive damage not only is directly related to the application and effectiveness of punitive damage system, but also has a vital influence on food production industry and the related investment organs.

\section{A. Model assumption}

Although the standard of punitive damage has not been unified among theorists in China, from the perspective of the legislative experiences in other countries or regions, to adopt a flexible punitive damage system with more discretionary space has been the tendency for the punitive penalty in many countries. Based on literature review and the prospect theory, this paper holds the following assumptions.

First, once the illegal behavior of food enterprises is found out by supervision authorities, they will get deserved punishment. The probability of "being exposed or found out" is $q(0<q<1)$; the illegal gains without being exposed is $\psi$.

Second, the setting amount of punishment is important. Since the punitive damage is established based on compensatory, namely equalization principle, and based on the three fundamental features of Prospect Theory when people make decisions, suppose the measure of punitive damage, not including the compensatory amount $(g)$ is directly related to gains from illegal production or operation. The correlation coefficient is named as the punitive damage coefficient $\theta$, and the total of punitive damage is $\theta \psi+g$.

Third, suppose the gains and losses of production and operation of food enterprises is measured by currency, and gains of legal production and operation $\psi_{0}\left(\psi_{0}<\psi\right)$ is regarded as the reference point of risk decision.

\section{B. Modeling}

According to the Prospect Theory, neglecting other external effects and taking the legal gains as the standard, when illegal operation of food enterprises are not disclosed, the compensatory amount $(g)$ will be taken as the gains, and therefore the value perception for the illegal gains can be expressed by $v\left(\psi+g-\psi_{0}\right)$; when the illegal operation of food enterprise is unveiled, the value perception for the illegal gains can be expressed by $v\left(\theta \psi+g-\psi_{0}\right)$. Therefore, the impact mode of production and operation behavior of food enterprises under the system of punitive damage can be expressed as the equation (3).

$$
\left\{\begin{array}{c}
\operatorname{Max} V(g)=\pi(1-q) v\left(\psi+g-\psi_{0}\right)+\pi(q) v\left(\theta \psi+g-\psi_{0}\right) \\
\text { s.t. }(g) \geq 0, g \geq 0
\end{array}\right.
$$

\section{Impact analysis}

From the impact mode of production and operation behavior of food enterprises under the system of punitive damage, whether food enterprises violate the law mainly depends on the compensatory amount $(g)$, punitive damage coefficient $(\theta)$, illegal gains $(\psi)$ and legal gains from production and operation $\left(\psi_{0}\right)$. To simplify the above mode, let $\tau_{1}=\psi+g-\psi_{0}, \tau_{2}=\theta \psi+g-\psi_{0}$, we can obtain:

$$
\operatorname{Max} V(\psi)=\pi(1-q) v\left(\tau_{1}\right)+\pi(q) v\left(\tau_{2}\right)
$$

Optimize (4), acquire the total differential and simplify it into:

$$
\frac{d \tau_{1}}{d \tau_{2}}=-\frac{\pi(q) v^{\prime}\left(\tau_{2}\right)}{\pi(1-q) v^{\prime}\left(\tau_{1}\right.}
$$

If food enterprise chooses illegal production and operation to maximize its interests, then, we can obtain the following:

$$
\begin{gathered}
\frac{\partial V(\psi)}{\partial \psi}=\pi(1-q) v^{\prime}\left(\tau_{1}\right)-\theta \pi(q) v^{\prime}\left(\tau_{2}\right) \\
\text { Let } \frac{\partial V(\psi)}{\partial \psi}=0 . \text { We can get } \theta=\frac{\pi(1-q)}{\pi(q)} \times \frac{v^{\prime}\left(\tau_{1}\right)}{v^{\prime}\left(\tau_{2}\right)},
\end{gathered}
$$

the optimal punitive damage coefficient. According to the prospect theory, when $\tau_{2} \geq 0,0 \leq v^{\prime}\left(\tau_{1}\right)<v^{\prime}\left(\tau_{2}\right)$, we can obtain $\theta=\frac{\pi(1-q)}{\pi(q)} \times \frac{v^{\prime}\left(\tau_{1}\right)}{v^{\prime}\left(\tau_{2}\right)}<\frac{\pi(1-q)}{\pi(q)}$; when $\tau_{1}<0$, $0 \leq v^{\prime}\left(\tau_{2}\right)<v^{\prime}\left(\tau_{1}\right) \quad, \quad$ we can acquire $\theta=\frac{\pi(1-q)}{\pi(q)} \times \frac{v^{\prime}\left(\tau_{1}\right)}{v^{\prime}\left(\tau_{2}\right)}>\frac{\pi(1-q)}{\pi(q)}$. Thus, in order to strengthen the deterrence of punitive damage system in food industry and contribute to the legal environment for food enterprises to operate, the punitive damage coefficient can be determined as follows.

$$
\theta=\pi(1-q) / \pi(q)
$$




\section{Simulation analysis of the optimal punitive damage coefficient}

To analyze the impact mechanism of the optimal punitive damage on the decision making of food enterprises, combine equations (2) and (7), the following equation (8) can be obtained.

$$
\theta=\pi(1-q) / \pi(q)=[(1-q) /(q)]^{\gamma}
$$

By analyzing the risk attitude coefficient $\gamma$ $(0<\gamma<1)$ and the probability of "illegal operation unveiled" $q(0<q<1)$, the changing rules of optimal punitive damage coefficient is explored and the optimal $\theta$ can be determined. By means of matlab7.0, simulation analysis is conducted and results are shown in the following figure.

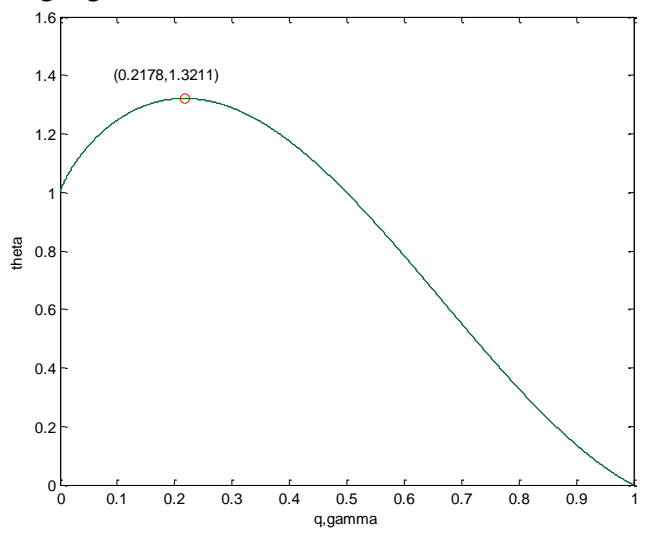

Figure 2. The change chart of punitive damage coefficient

From Fig.2, the punitive damage coefficient $\theta$ first increase and then decrease, which means the value of $\theta$ should be determined by the risk attitude coefficient of food enterprises and the probability of "illegal operation unveiled" $q$, rather than the fixed compensation mode of "a penalty 10 times of the paid amount". Meanwhile, to deal with the high supervision cost, large supervision objects and supervision failure of food industry in China, this paper proposes that the punitive damage coefficient should be controlled within the range of $[1,1.3211] . \theta$ in this range can not only meet the flexibility demand of punishment, but also gives more discretionary space. Furthermore, the setting of the highest punitive damage coefficient will be conducive to the prevention of consideration and decision abuse of the judge and the jury and so that the legal gains of food enterprises can be ensured.

\section{CONCLUSION}

Based on the Prospect Theory, this paper analyzes the punitive damage system in Food Safety Law of the People's Republic of China, and investigates the causes for food safety incidents. It builds an impact model of food enterprise's operation behaviors under the punitive damage system. Simulation analysis is conducted to acquire the optimal range of the punitive damage coefficient. Conclusions of this paper are mainly as follows. First, an improved punitive damage system of food safety should be established to increase the illegal cost of food enterprises, minimize its illegal behaviors and safeguard the rights of consumers. Second, the optimal punitive damage coefficient $\theta$ should meet $\theta=[(1-q) / q]^{\gamma}$. Third, the optimal range of punitive damage coefficient is within [1, 1.3211]. Based on the above conclusions, corresponding suggestions are as follows. First, to adjust the standard base of punitive damages: the original standard base of punitive damages is calculated by the measure of interests from illegal or unsafe food products and illegal profits, i.e., the standard base=Prices of products+Illegal profits. Second, to formulate a flexible punitive damage system with more discretionary space and offer a recommended calculation of punitive damages: prices of products plus $[1,1.3211]$ corporate earnings.

\section{ACKNOWLEDGMENTS}

The authors acknowledge the financial support from the Yunnan Food Safety Institute of China (Nos. KKSTJ201358017).

\section{REFERENCES}

[1] D. Linna. "An economic analysis and system suggestions of illegal behaviors in food safety from the perspective of illegal cost," Inquiry Into Economic Issues, vol. 12, 2012, pp.36-40.

[2] X. M. Xi. Interpretation and Application of the Tort Liability Law of the People's Republic of China [M]. People's Court Press, 2010.

[3] L. Zhang, G. Z. Zeng. "Analysis of Chinese Food Safety Legal System,". Hebei Law Science, vol.30, 2012, (7): pp.139-142.

[4] J. Wang, J. Zhong. "Reestablishment of Punitive Compensation System for Food Safety,". Social Science of Beijing, vol. 6, 2012, pp. 21-26.

[5] X. Li. "On Punitive Damages in Food Safety Litigation," Social Science of Beijing, vol. 4, 2013, pp. 87-91.

[6] M. Yan. "Suggestions on the provisions of China Food Safety Law," Journal of Socialist Theory Guide, vol. 6, 2014, pp. 101-103,108.

[7] L. P. Huang, C. Ju. "Study of the punitive damages in Food Safety Law of China," Ianghan Tribune, vol. 12, 2009, pp. 135-138.

[8] P. Li, S. Li, J. J. Zhu, et al. "Intuitionistic fuzzy stochastic multi-criteria decision-making methods based on MYCIN certainty factor and prospect theory," Systems Engineering: Theory \& Practice, vol. 33, 2013, pp. 1509-1515.

[9] D. Kahneman, A. Tversky. "Prospect theory : An analysis of decision under risk," Economic, vol. 47, Feb. 1979, pp. 263-291.

[10] Z. Q. Wang, J. H. Liu. "Law of Economy Analysis of Large Scale Food Infringement," Commercial Research, vol. 1, Dec. 2011, pp 200-206.

[11] T. C. Wu, C. H. Chen, C. C. A. Li. Correlation among satefy leadership, safety climate and safety performance[J]. Journal of loss prevention in the process industries, 2008, 21(3): 307-318. 